\title{
Is the oil industry able to support a world that consumes 105 million barrels of oil per day in 2025?
}

\author{
Pierre Hacquard ${ }^{1}$, Marine Simoën $^{2,3}$, and Emmanuel Hache ${ }^{2,3,4,{ }^{*}}$ \\ ${ }^{1}$ Equinor, Forusbeen 50, 4035 Stavanger, Norway \\ ${ }^{2}$ IFP Energies nouvelles, 1-4, avenue de Bois-Préau, 92852 Rueil-Malmaison Cedex, France \\ ${ }^{3}$ The French Institute for International and Strategic Affairs, (IRIS), 75011 Paris, France \\ ${ }^{4}$ EconomiX-CNRS, University of Paris, Nanterre, France
}

Received: 10 October 2019 / Accepted: 8 November 2019

\begin{abstract}
This paper investigates the significant risk of a supply crunch in the oil market by 2025 and beyond, given current pace of investment and growth of world demand. We focus particularly on today's upstream sector and the challenges it faces in meeting the ever-increasing demand for oil. We then study different production scenarios for U.S. unconventional oil potential and draw conclusions on its potential capability to offset the weakening context of conventional oil supply (declining production, declining discoveries, insufficient investment, persistent geopolitical risks and environmental pressures). We conclude that with growing oil demand, the probability of an oil crunch by 2025 is far from null.
\end{abstract}

\section{Introduction}

The evolution and future of the global energy system has always been at the heart of concerns of governments, international institutions and energy companies due to its fundamental role in economic, political, environmental and climate issues. In 2018, worldwide oil production has reached for the first time the amount of 100 million barrels per day (mb/d) (IEA, 2018). Behind this symbolic benchmark is a constant trend spanning several decades: a growing economy that requires abounding amount of oil. Thus, an ever-increasing need to expand the world's supply of cheap and accessible energy services in parallel with a push to cope with the $2{ }^{\circ} \mathrm{C}$ objective of the Paris Agreement implies strong uncertainties about the future of the global energy system.

Being able to precisely understand the potential trajectories of commodities supply and demand as well as their associated uncertainties are the keys to provide decision makers with relevant and exhaustive analysis. Thus, a significant amount of prospective energy system modelling has been carried out by a variety of actors such as research institutions, inter-governmental organizations and private energy companies. The model results are heavily dependent on specific assumptions, covering macro-scenarios (e.g., economic growth, demography, climate constraints, etc.) and degrees of technological evolution. There is much room for debate around those assumptions, as no model can truly

\footnotetext{
* Corresponding author: emmanuel.hache@ifpen.fr
}

replicate the reality of the world's complexity (Grandjean et al., 2019). However, they provide valuable insights on major future trends and largely contribute to influence global leaders' decisions and economic variables such as private investments.

One of the most renowned institutions in energy modelling is the International Energy Agency (IEA) founded by the Organization for Economic Co-operation and Development (OECD) in 1974 in reaction to the first oil shock and the Middle East Crisis. Initially designed to anticipate and react to physical oil supply disruption and as source of data related to the oil market situation and other energy sectors, the IEA is now a broad world policy advisor on energy security, economic development and environmental protection. Consequently, every year the IEA publishes its World Energy Outlook (WEO) in which all the energy-related trends are analysed and assessed. Although it is now focused on all kinds of energy sources, the oil market remains at the heart of the institution's concerns and its analysis remains the most awaited and read by the various stakeholders. Most of the players of the oil industry (i.e., ExxonMobil, Total, Equinor, BP, DNV GL, etc.) use and compare their own foresight and scenarios with the IEA analysis.

In this outlook, three main scenarios are described (IEA, 2018):

- the Current Policies Scenario (CPS) solely based on existing laws and regulations, therefore excluding the ambitions and targets that have been declared by governments around the world, 


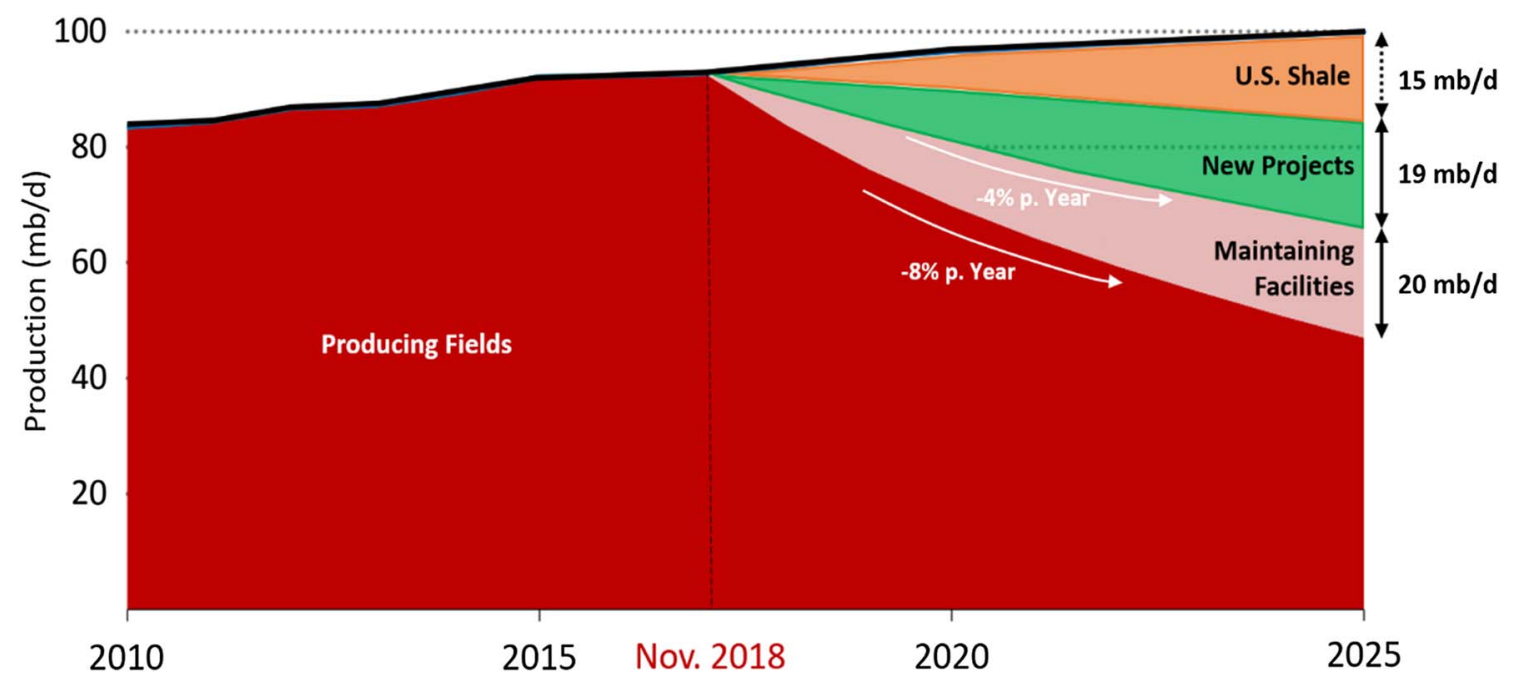

Source: authors modified from IEA, World Energy Outlook, 2018

* What is recorded in a barrel may vary from one institution to another. IEA's specific accounting system will be used in this article (IEA,2018).

Fig. 1. Crude oil demand and supply forecast in the NPS scenario*.

- the New Policies Scenario (NPS) providing a measured assessment of where today's policy frameworks and ambitions, together with the continued evolution of known technologies, might take the energy sector in the coming decades,

- the Sustainable Development Scenario (SDS) is a recent scenario exploring what it would take to reach the sustainable development goals of the COP21 in 2015 to limit global warming below $2{ }^{\circ} \mathrm{C}$ and providing a universal access to modern energy by 2030 .

The NPS being considered as a reference scenario, this paper will aim to discuss its oil demand and supply assumptions. Nevertheless, it is important to keep in mind that in its current form this scenario is not compatible with the $2{ }^{\circ} \mathrm{C}$ Paris agreement objective. The WEO 2018 NPS provides an overview of the evolution of demand and supply for oil by 2025 . From 99.2 million barrels per day $(\mathrm{mb} / \mathrm{d})$ in 2018, demand is expected to reach $106.4 \mathrm{mb} / \mathrm{d}$. This represents an annual average growth rate of $c a .1 .2 \mathrm{mb} / \mathrm{d}(1.2 \%)$ and a total volume increase of $7.1 \mathrm{mb} / \mathrm{d}$ (IEA, 2019b). IEA models then sweep away the eventuality of a peak in demand by 2025 and foresee a sustained increase even in a context of moderate economic growth. On the supply side, it can be observed that by 2025, the natural decline rate of already producing fields leads to an estimated $34 \mathrm{mb} / \mathrm{d}$ of new output needed to meet the demand. This number reaches $54 \mathrm{mb} / \mathrm{d}$ if the required investments to maintain current facilities are not sanctioned (Fig. 1). This corresponds to an estimated $5.5-9 \mathrm{mb} / \mathrm{d}$ to be replaced every year and it represents the equivalent of 3-4 times the output from Saudi Arabia, in just 6 years.

According to the IEA, at current rates of project approval and if existing facilities are maintained, $19 \mathrm{mb} / \mathrm{d}$ could be supplied by new projects, excluding U.S. unconventionals. Nevertheless, an additional $15 \mathrm{mb} / \mathrm{d}$ would still be needed to avoid a supply crunch by 2025 and beyond. Considering the current state of the oil market, only one source of supply seems able to fill this gap in such a short-time frame: the U.S. unconventional production. But to achieve this amount of production, actual level of production would have to double $(7.419 \mathrm{mb} / \mathrm{d}$ estimated by the U.S. Energy Information Administration in April 2019).

Thus, for the first time ever since its first publication, the IEA clearly states the fortuity of a supply crunch by 2025: "The risk of a supply crunch looms largest in oil. The average level of new conventional crude projects approvals over the last three years is only half the amount necessary to balance the market out to 2025, given the demand outlook in the New Policies Scenario. US tight oil is unlikely to pick up the slack on its own. Our projections already incorporate a doubling in US tight oil from today to 2025, but it would need more than triple to offset a continued absence of new conventional projects" (IEA, 2018).

In this context, it seems interesting to focus on the two following questions: (i) why does the IEA not rely on other sources of supply than the U.S. unconventional oil to match the demand and (ii) can the U.S. unconventional oil truly produce $15 \mathrm{mb} / \mathrm{d}$ by 2025 ?

In this paper, we will then highlight the main factors that can limit the ability of U.S. unconventional oil to fill the gap between a quickly declining production and a rising demand.

The first section of this article will focus on analysing the today's upstream sector and the challenges it faces in meeting the ever-increasing demand for oil. To probe the ability of U.S. unconventional oil potential to offset this 


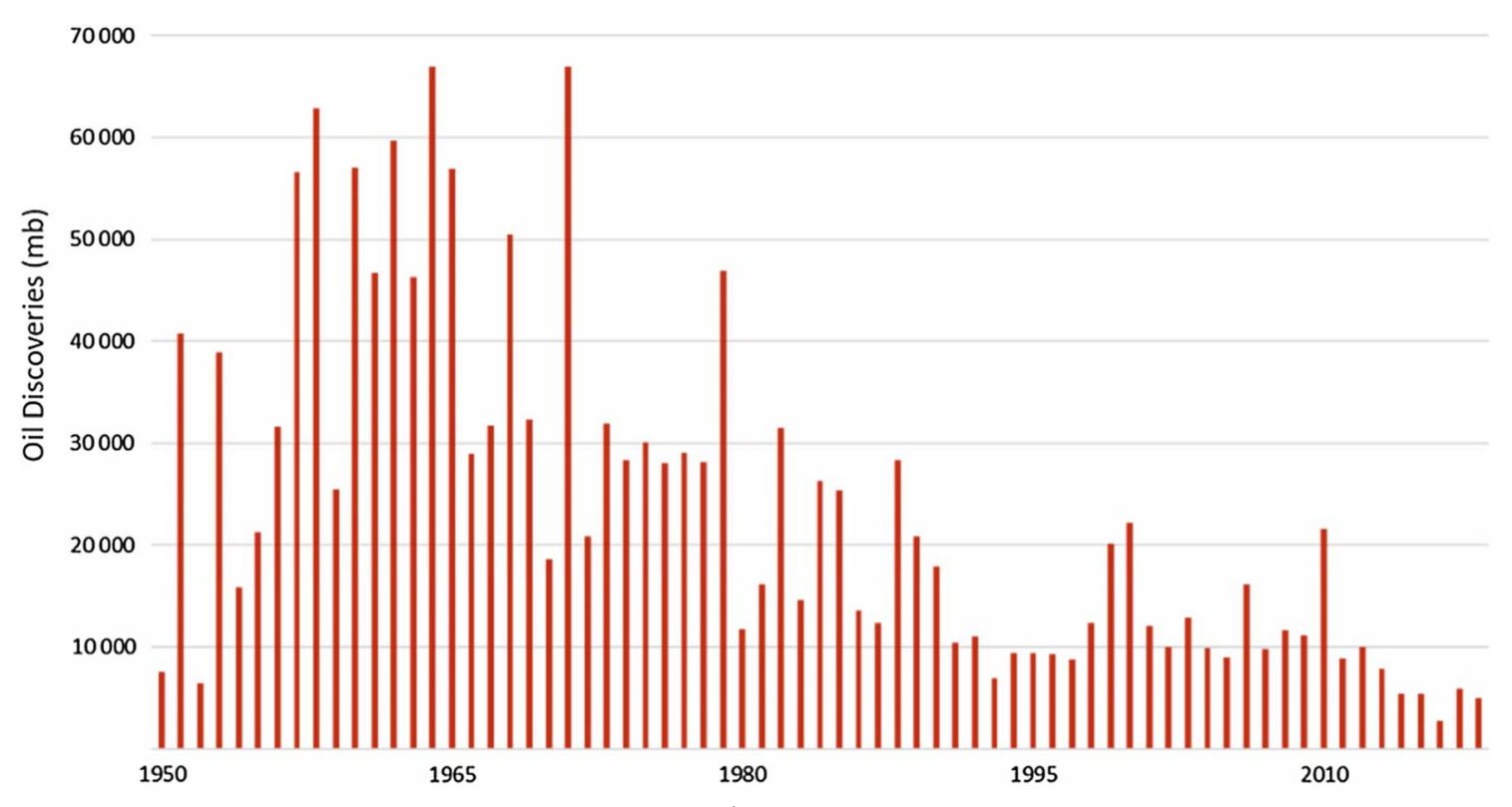

Source: Rystad Energy, 2018; 2019

Fig. 2. Historical of conventional oil discoveries.

potential supply deficit, the second section will study different production scenarios. Results are finally discussed in Section 3, in parallel with unconventional oil production limits for other regions. The conclusion of this article confirms the significant risk of a supply crunch by 2025 and beyond at current pace of investment and growth of oil demand.

\section{Factors weakening the upstream sector}

\subsection{Declining conventional resources}

The peak of conventional oil resources discoveries has been reached decades ago, with number of discoveries steadily decreasing since then (Fig. 2). If there are still conventional discoveries nowadays (Rystad Energy, 2018) ${ }^{1}$, most of them are non-conventional resources such as U.S. unconventional oil or oil sands in Canada. Following the 2014 downturn of oil prices, discoveries have hit a record low over the last 4 years with less than 9 billion of barrels oil equivalent (bnboe) discovered per year (Rystad Energy, 2019).

Discovered volumes from high impact drilling (>100 mb drilling targets) fell overall by $50 \%$ in this period compared to the previous 5 years. The lower drilled well count which fell by $28 \%$ over the period only account for less than a half of this drop (Fig. 3), falling commercial success rates and average discovery sizes accounted for the rest.

As a result, portfolio renewal has become a critical issue for the oil industry. Over the last 5 years the commercial

\footnotetext{
${ }^{1}$ In 2018, according to Rystad Energy most of the conventional discoveries were located in Guyana (2 bnboe), Russia (1.3 bnboe), the U.S. (0.746 bnboe), Cyprus (0.67 bnboe), Oman (0.67 bnboe), Norway ( 0.5 bnboe), Australia ( 0.35 bnboe), the United Kingdom (0.3 bnboe), Gabon (0.2 bnboe) and Malaysia (0.19 bnboe).
}

success rate for frontier exploration ${ }^{2}$ has just hit $6 \%$ for 154 wells at a cost of USD 11 billion (Westwood Global Energy Group, 2019). The low success rate in exploration, along with low oil prices, led the upstream industry to reduce its exposure to risk by cutting exploration budget from $20 \%$ of total investment in 2010 to a record low of $10 \%$ in 2018 (IEA, 2019a). Most of the main Exploration and Production companies have increased their investment in improving production from existing fields. Only a handful of companies with significant levels of production have been able to replace their produced reserves solely through exploration (Westwood Global Energy Group, 2019). A direct consequence of this increased difficulty to discover new reserves is also the rising trend in mergers and acquisitions observed in the oil sector over the past few years (Fosse et al., 2015).

On top of that, the average size of discoveries has in the same time drastically fallen from $500-1000$ mmboe $^{3} 40$ years ago to 50-100 mmboe over the last 5 years. It steadily decreased year after year and reached a historic low of 57 mmboe in 2018 (Westwood Global Energy Group, 2019).

A conventional oil field will reach its peak of production during the first year after commissioning before entering a phase of irreversible exponential decline called the decline phase. Estimation of the decline rate may vary depending on the field characteristics between $3 \%$ and $9.5 \%$ per year. Around $81 \%$ of the global liquid production is now in the decline phase (BP, 2018; Fustier et al., 2016; IEA, 2018). Nowadays, the global supply mix rely increasingly on small fields. And the smaller the fields, the faster their

\footnotetext{
${ }^{2}$ A frontier exploration well is considered to target underexplored areas or concepts with high risks but high potential discovery sizes.

${ }^{3}$ Million Barrels of Oil Equivalent.
} 


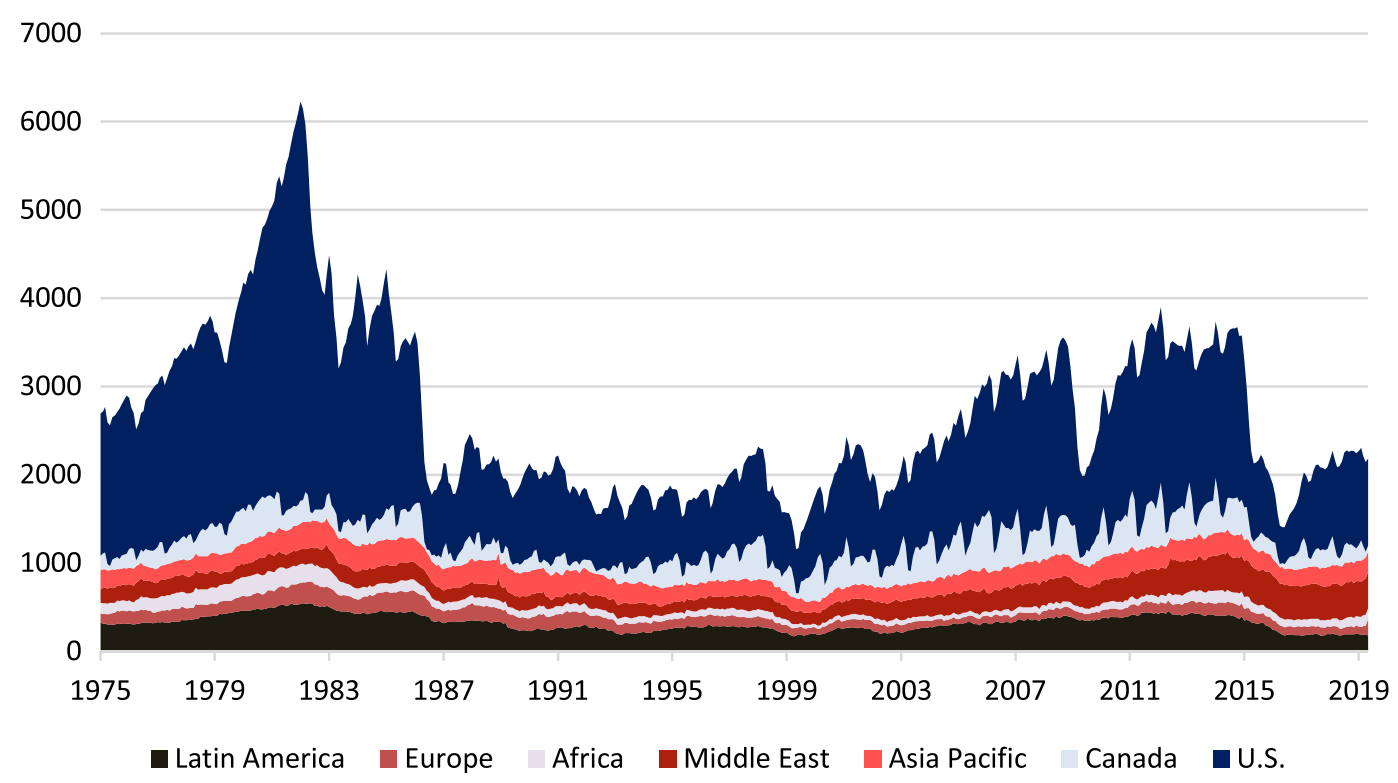

Source: BHGE Rig Count, May 2019

Fig. 3. Global rig count.

production declines. Thus, the new fields have a decline rate twice as high as what was observed 40 years ago on large fields.

Consequently global conventional crude oil production peaked in 2008 at $69 \mathrm{mb} / \mathrm{d}$ (IEA, 2018) and has since fallen by c.a. $2.5 \mathrm{mb} / \mathrm{d}$ without any expected recovery soon. Only the developments of NGLs ${ }^{4}$, Extra-Heavy Oil \& Bitumen (EHOB) and Tight Oil have compensated this decline and allowed the global economy to keep growing (IEA, 2018). To satisfy the demand without massive support from U.S. unconventionals, at least 16 bnboe must be discovered by 2025 every year. Almost twice as much as current levels (IEA, 2018).

As mentioned before, the number of active conventional and unconventional drilling rigs in the world has been reduced by $28 \%$ since 2014 highs. Of the 2182 rigs in operation in May 2019, half were located in North America (of which $93 \%$ in the U.S., Fig. 3). Currently, $87.2 \%$ of the U.S. rigs are dedicated to horizontal wells drilling, meaning that about a half of all the wells drilled in the world today are dedicated to unconventional resources (BHGE, 2019). The number of rigs is relatively elastic and could quickly increase again if oil prices and market conditions return to more appealing levels. However, it is important to highlight that most of this flexibility can be observed only in the U.S. where the production's factors can be mobilized quickly.

\subsection{Insufficient investment}

Following 2014 and the drop of oil prices from more than $100 \$$ per barrel to less than $45 \$$ in annual average in 2016

\footnotetext{
${ }^{4}$ Natural Gas Liquids (NGL) are components of natural gas that are separated from the gas state in the form of liquids.
}

(Fig. 4), capital expenditure in the upstream part of the oil industry have been significantly reduced by around USD 1-2 trillion (Fig. 5). The consequences of this drastic reduction are still uncertain and have not yet been felt on global production.

In 2018, investments in the upstream sector were still $40 \%$ lower than those observed in 2014. Most of this contraction is due to lower investment volumes. However, companies also benefit from a favourable price environment from their suppliers under pressure. Adjusted to current upstream costs, it still represents a $12 \%$ lower investment compared to the 2014 peak. Another major difference is that Tight oil investments now represent $26 \%$ of all upstream investments compared to $17 \%$ over $2010-2015$ (IEA, 2019a).

There are many factors that can explain the decreasing trend in investment following the oil crisis of 2014, (i) the low oil price perspective due to unconventional crude oil entering the market rapidly; (ii) this trend has also a negative impact on Oil and Gas companies share prices which then focus on maintaining dividend level (buy-back program, etc.) and not investing in new projects; (iii) the switch to renewable strategies for many Oil and Gas companies (BP, Total, Equinor, Royal Dutch Shell, etc.) impacting the amount of their budget dedicated to Oil and Gas project; (iv) the banking system has less and less incentives to finance risked Oil and Gas projects due in particular to social pressures coming from shareholders; (v) risk averse strategies have lowered the exploration budget of most of the big Oil and Gas companies, focusing on improving the production of existing fields as well as doing near field exploration (less capital intensive but lower volumes discovered); (vi) the BP accident in the Gulf of Mexico and the fine resulting of this accident $(20 \mathrm{bn} \$+)$ had an impact on budget dedicated to safety and HSE for most 


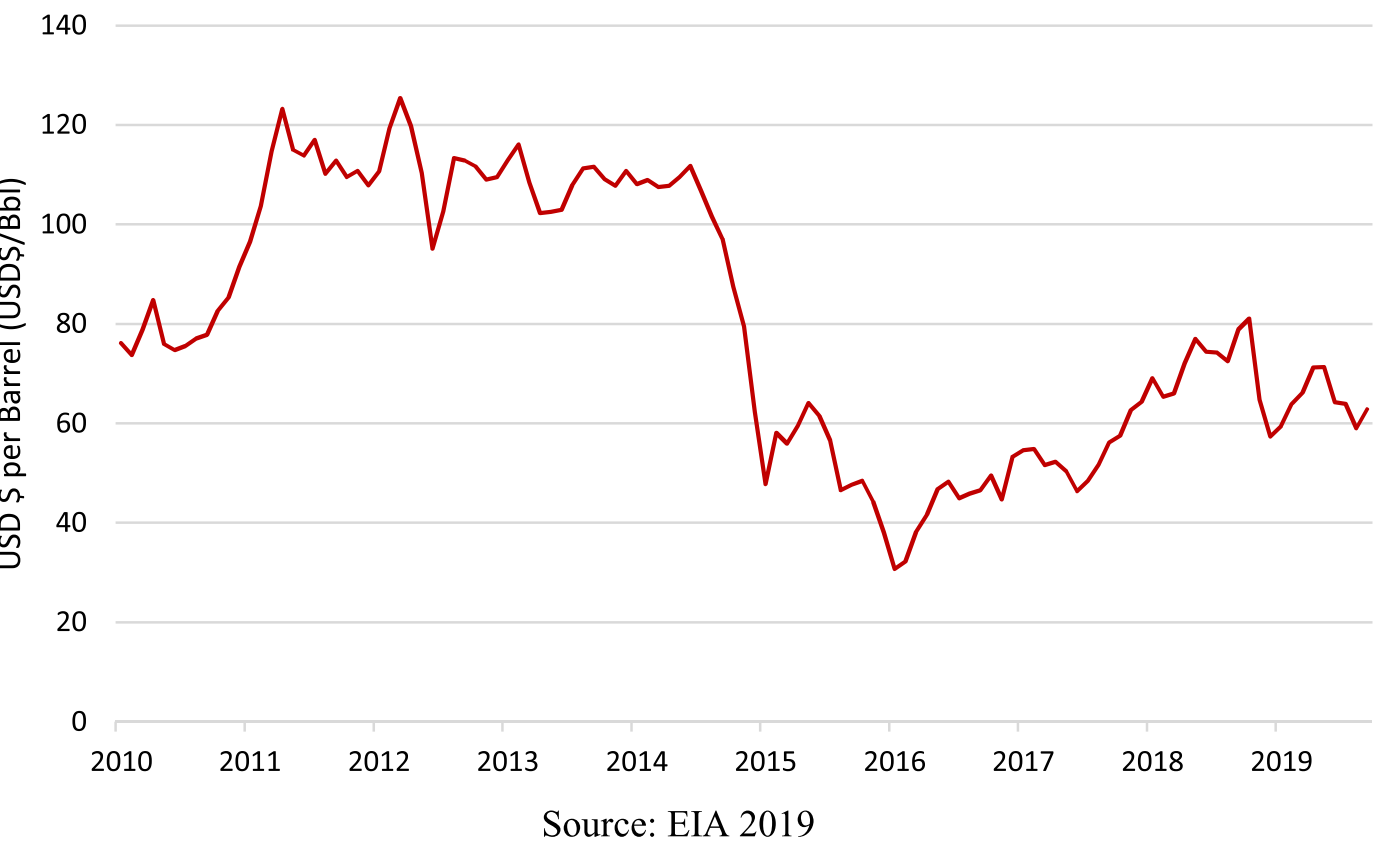

Fig. 4. Historical Brent oil price in nominal USD $\$$ per Barrel.

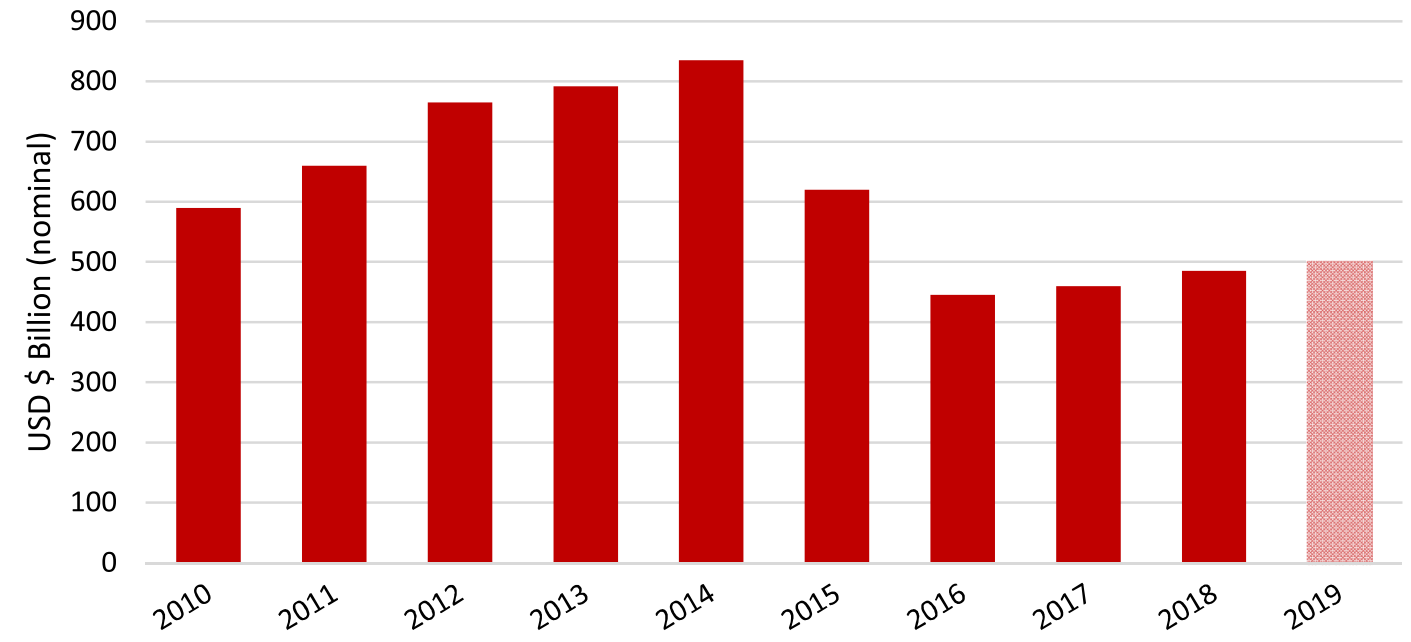

Source: IEA, World Energy Investment, 2019

Fig. 5. Global upstream oil and gas investment in nominal USD $\$$ billion.

of the international companies; (vii) public pressure has slowed down some processes in the world to provide licenses and permit to drill (Lofoten islands in Norway for example) and recently (viii) the trade war between China and the U.S. has affected the world economic growth perspectives and the oil consumption growth in the middle run.

For another consecutive year, global investment growth in upstream is then expected to remain moderate in 2019. It is estimated between $3 \%$ and $8 \%$, compared to exceeding
15\% prior to the 2014 low point (IFPEN, 2019a). Moreover, there are sizeable regional disparities, principally between North America (investment growth rate of $18 \%$ ) and the rest of the world $(+2 \%)$. This difference is simply explained by massive investment in U.S. unconventional oil which represents $21 \%$ of global investments in the U.S. (IEA, 2019a). The projects developed are carried out in a context of depressed service prices and are mainly focused on shallower, less capital-intensive offshore environments (IFPEN, 2019a). 


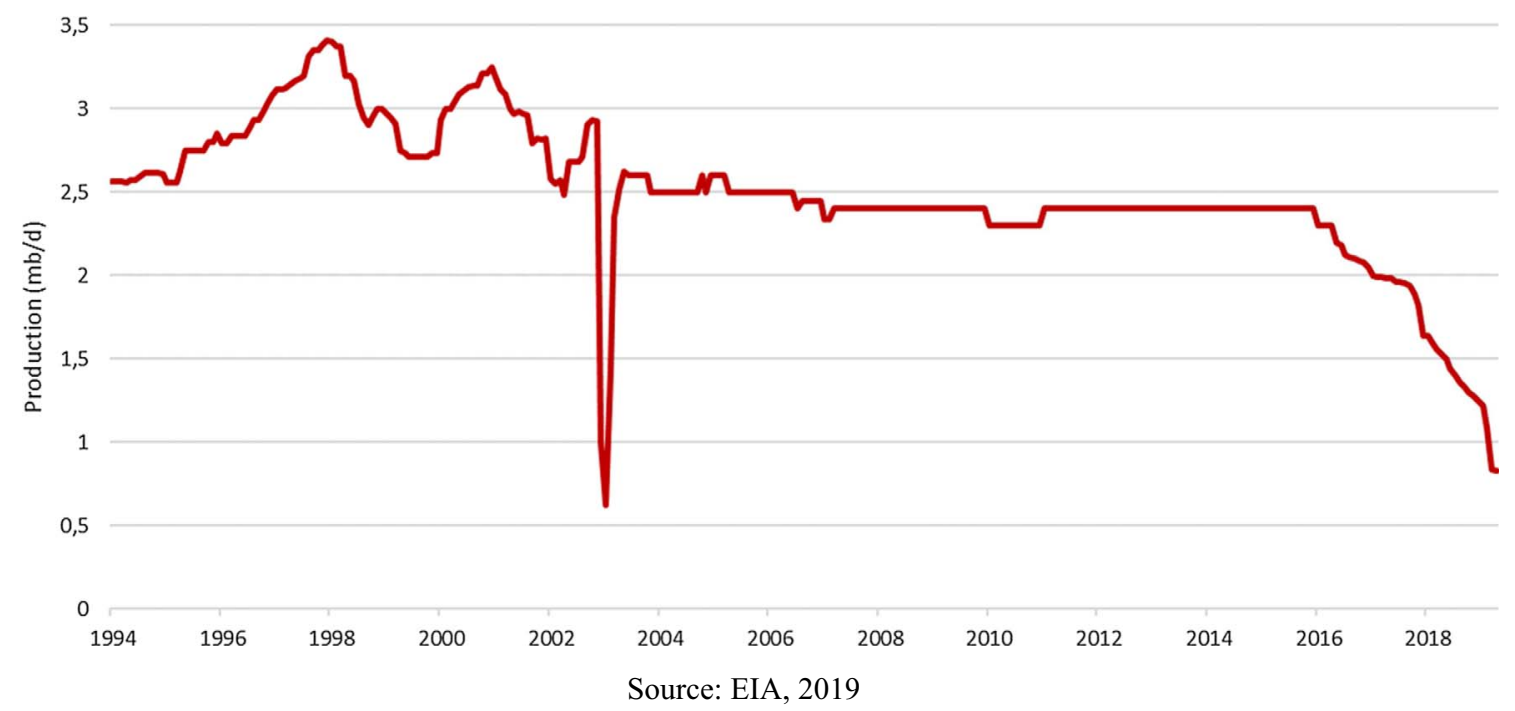

Fig. 6. Historical Venezuelan oil production.

\subsection{Persistent geopolitical risks}

Recent geopolitical instabilities and societal uncertainties have also affected the supply capacity of important producers and it is highly probable that it will happen again in the future. Overall, the geopolitics of energy lies at a crossroads between the founding structural elements of the second half of the 21st century, current economic factors and the geopolitics resulting from the integration of renewable energies into the global energy mix (Bonnet et al., 2019; Hache, 2016; Hache et al., 2019a, b). Current concerns are concentrated in a few specific areas, mainly in the Middle-East and more recently in the Hormuz Strait but also in Venezuela and Libya.

Following their withdrawal from the Iranian nuclear agreement established in 2015, the U.S. will aim at achieving a total halt on Iranian crude oil purchases. It was associated with sanctions on countries that keep on buying it, at the risk of tensions with several allies. The maximum shortfall could cover a volume up to $2.7 \mathrm{mb} / \mathrm{d}$, the average exported volume recorded at the beginning of 2018 . More recently, tensions in the Hormuz Strait suggest increasing disruptions in a region where around $20 \%$ of the global oil production is transiting every day (EIA, 2019). In Libya, onshore drilling activities just resumed after 3 years of interruption. Recent tensions casted doubt on the ability of its industry to recover in a context of more expensive and complex projects. Between 2012 and 2013, production had already been divided by 6 (IFPEN, 2019b). Having seen one of the biggest ever annual declines in 2018 (Fig. 6), production in Venezuela will continue to fall as its economy lurches deeper into crisis. The cash crunch at Petroleos de Venezuela ( $P D V S A)$ and poor reservoir management have already cut output by nearly $1.6 \mathrm{mb} / \mathrm{d}$ over the past 3 years. U.S. financial sanctions enforced in January 2019 should compound the losses (IEA, 2019b).
Such supply-side pressures are by nature very difficult to anticipate and add significant uncertainties about the stability of the global oil supply system in the short-run.

\subsection{A new environmental deal}

An important aspect of the risks that weigh on the future of upstream capacities and that should not be taken lightly are the climate and environmental issues we face and their increasing influence on economies, consumer behaviour and policy-makers. Consumers are increasingly in demand for more transparency from states and institutions all over the world. Intensive lobbyism and activism have led to historical recent decisions that will affect long term oil supply. Recently, several commitments made by leading oil majors, such as Equinor, BP or Royal Dutch Shell have been observed at the Climate Action 100+ investor group and more are to come. Other majors such as Total have committed to become carbon neutral by 2030. It will necessarily have an impact on their investments, which will no longer be entirely dedicated to renewing their oil reserves but also to develop new low-carbon businesses. Some companies have even completely disengaged from their fossil activities in the image of the French energy giant Engie 5 .

Due to the poor image of the oil industry by younger generations, raising fears of a shortage of talent in the coming years is becoming a critical issue. The energy industry was solely ranked sixth amongst the eight main industries by Engineering and IT students and only one energy major was among the world's top 50 most attractive employer in 2018 (Universum, 2019).

\footnotetext{
5 The recent switch of strategy of Engie aiming to become a leader in "Zero-Carbone" energy transition was followed by the full divestment from all its E\&P activities, sold to the UK company Neptune in 2017.
} 
Anti-oil policies are making their path through the political landscape. In France, all exploration projects have recently been banned from 2040 onwards. The Norwegian sovereign fund, the largest in the world, has just announced its withdrawal from all pure exploration players in the coming years. In the financial sector many banks, mainly European but also American, driven by shareholder demands, have decided to withdraw from investing in the Canadian Oil Sands or in U.S. unconventionals.

While these few examples may seem anecdotal in terms of impact today, they constitute "weak signals" sent to the rest of the international community for tomorrow. The disinvestment in the upstream sector is likely to increase in the future and is no longer solely a result of market price variations.

These short and non-exhaustive factors underline the increasing challenges of the upstream sector to match a future growing oil demand. In addition to the decline in geological resources, many economical, societal and geopolitical aspects are making the market more complex and uncertain (Equinor, 2018; Hache et al., 2019b). Following the same observations, the IEA states for the first time in the WEO 2018 that at current pace of investment and discoveries, the industry will be able to provide the world with the oil it needs only if the U.S. unconventionals double their production by 2025 . Indeed, with a relative political stability, half of the world rig capacities, abundant source of cash and an already developed industrial network and infrastructures, they appear as the only ones able to fill this gap in the near term. But, despite technological progress and important discovered reserves, can the U.S. unconventionals alone compensate the inevitable decline of the conventional fields? A closer look at the U.S. unconventional oil potential will be presented in the following part based on historical data and a new production potential model.

\section{Methodology}

To assess the potential of the U.S. unconventional oil and answer the question of whether or not it can meet the growing demand for fossil fuels in the middle and long term, a model has been developed. This latter does not aim at precisely forecasting the level of the U.S. unconventional oil production in the coming years. Based on historical trends it rather aims at estimating the limits of its capacities within the current framework of technological and investment evolution. Tight oil reservoirs are characterized by lower quality than conventional ones. They are compact with low permeabilities and porosities requiring some hydraulic fracking for producing their oil, resulting in very low, rapidly falling production rates. Unlike conventional fields where production ramps-up during several months or years, a U.S. unconventional oil well will reach its peak of productivity very quickly, about 1-2 months after its commissioning. It will then decline exponentially and lose up to $70 \%$ of its maximum productivity after the first year, and $90 \%$ after the second year of production (EIA, 2019). As a comparison, the average flow rates of unconventional wells are 10-100 times lower than conventional ones, leading to an increased number of wells required to achieve the same production. Thus, the two main parameters identified and used to calibrate and run the model, that have the strongest influence on U.S. unconventional oil production rate, are the number of horizontal wells drilled per year and the average productivity per well over time.

Over 125000 horizontal wells have been drilled to date in the U.S. The data provided by the U.S. Energy Information Administration (EIA) highlights two distinct linear trends in annual drilling rates over the U.S. unconventional oil boom period (2010 to now) (EIA, 2019). The first trend associated with the 2010-2014 high oil prices has seen on average c.a. 15500 horizontal wells drilled per year. It is the highest rate of horizontal well drilling observed so far and will be considered as the "High Drilling Rate" in the model. The current drilling trend can be observed following the oil price downturn from 2014 to now with c.a. 8000 Horizontal wells per year (Fig. 7). It is considered as the "Low Drilling Rate" in our model.

On the other side, the average productivity per horizontal well has tripled over the last 7 years in the U.S., offsetting the quick exponential decline in productivity after commissioning and allowing the current records production rate that no one had anticipated. Two hypotheses have then been put forward regarding the evolution of the productivity to assess the potential of the U.S. unconventionals. One that makes room for productivity improvements, where average productivity per well will continue to increase. This hypothesis reflects the possible evolution of the technology combined with an improved understanding of the subsurface. This increase in productivity has been set up following the average trend of improvement of the last 7 years (c.a. +50 bpd at peak production) (Fig. 8). The other one is considering that productivity will remain stable and won't increase or decrease over the coming years. In 2018, the peak of productivity averaged 647 bpd per well.

The model has been computed on a monthly basis where the production decline rate of a well is fixed for each month of production based on historical performance from the last 7 years.

Four scenarios will be presented using the hypothesis outlined above:

- High Drilling Rate - Productivity Increase (HDR - PI);

- High Drilling Rate - Stable Productivity (HDR - SP);

- Low Drilling Rate - Productivity Increase (LDR - PI);

- Low Drilling Rate - Stable Productivity (LDR - SP).

\section{Results and discussions}

At the end of 2025, the results of our modelling show that the HDR-PI scenario, where production is constantly increasing, reaches 14.1 mbopd. The HDR-SP scenario also increases continuously but at a slower pace to reach 10.2 mbopd. In the LDR-PI scenario, production decreases immediately before recovering, as the natural decline in production is offset by productivity improvements in new wells to reach 7.4 mbopd. The LDR-SP scenario sees its 


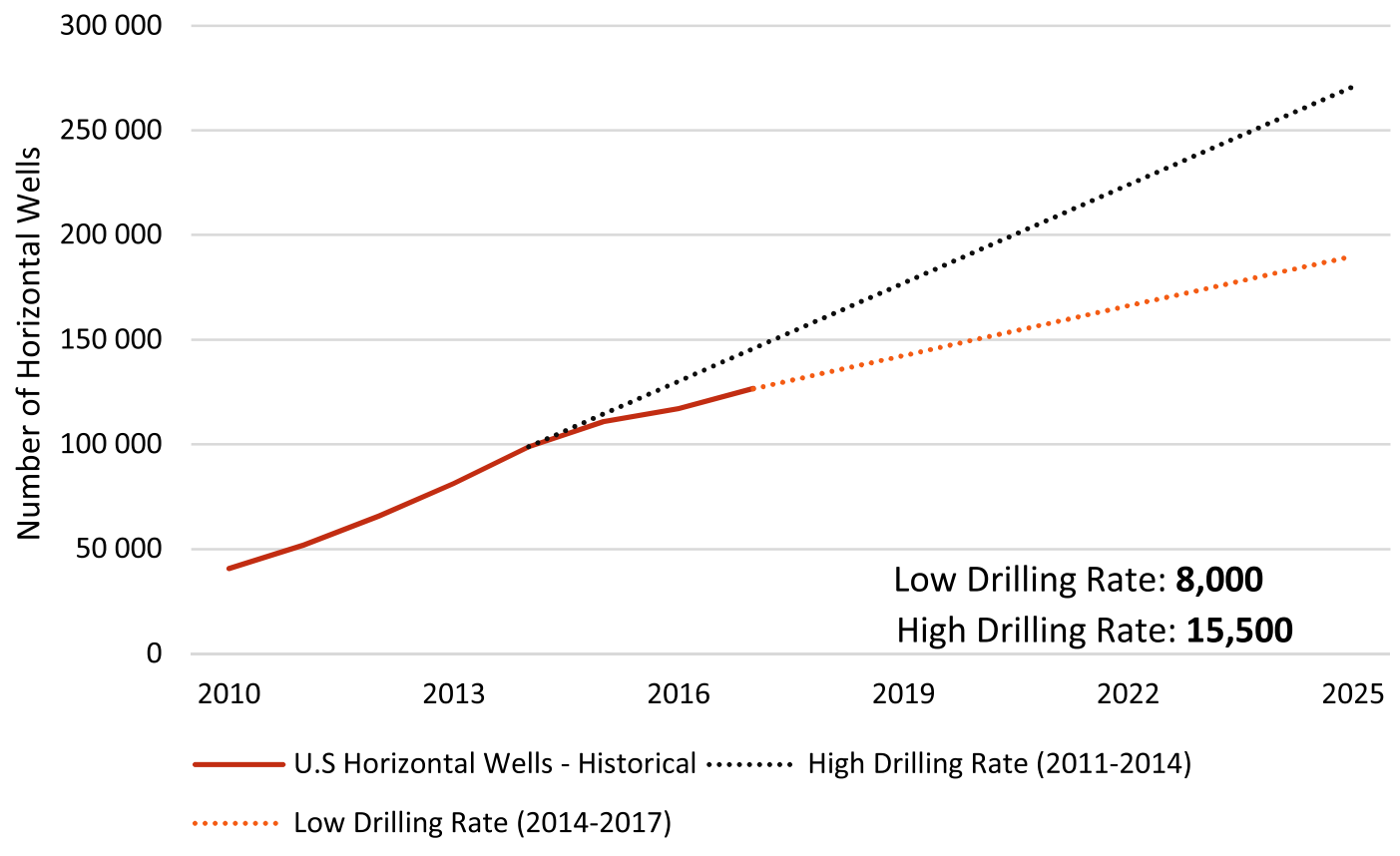

Source: EIA 2019; Authors projections

Fig. 7. U.S. Horizontal wells drilling rate models.

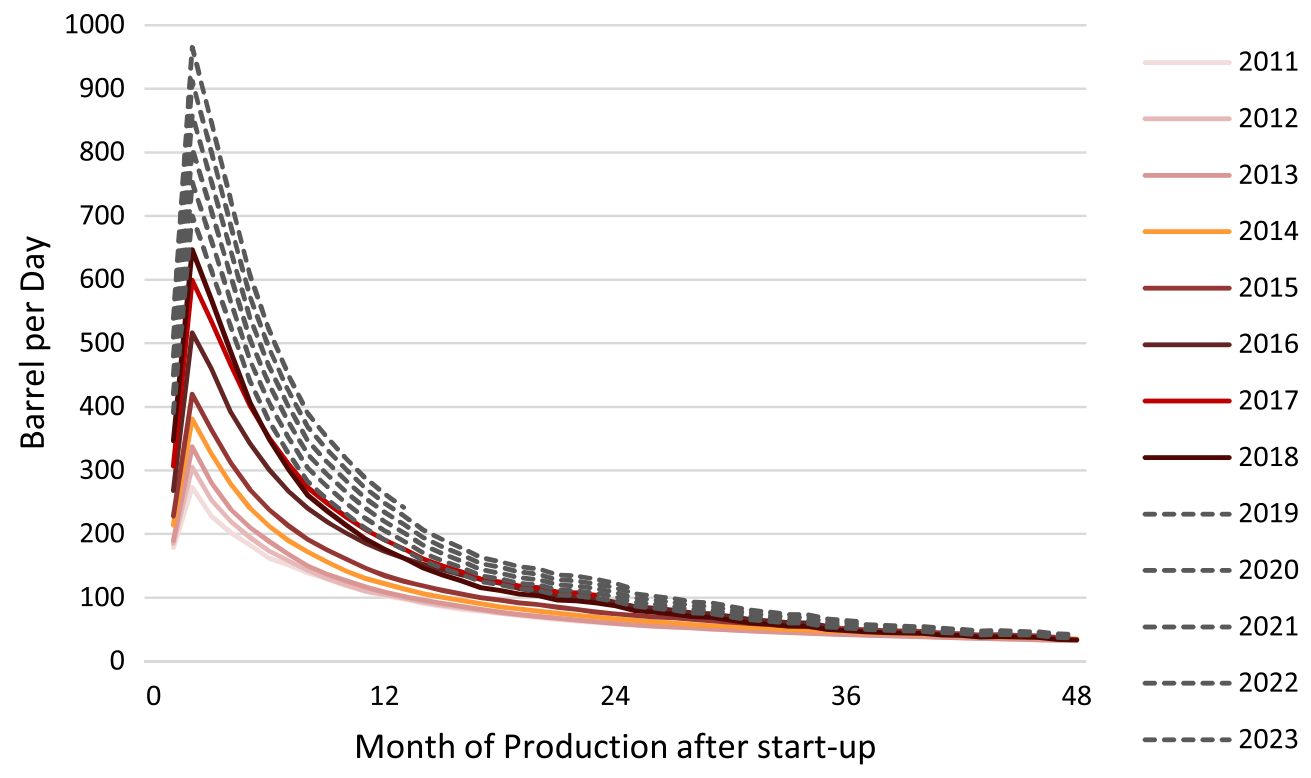

Source: EIA 2019; Authors projections

Fig. 8. Historical average productivity per horizontal well over time. The 2019-2025 forecast is based on the average increase in productivity per year over 2010-2018.

production continuously decreasing to reach 5.5 mbopd (Fig. 9). In all the scenarios the U.S. unconventional oil production is smaller than the 15 mbopd required according to the IEA to balance supply and demand in the coming years.

The hypotheses used in the model can be considered as optimistic when compared to additional parameters that can negatively affect the U.S. unconventional oil production:

- it is not considered that after a certain time, as for conventional fields, the most productive areas will have all been put into production and operators will 


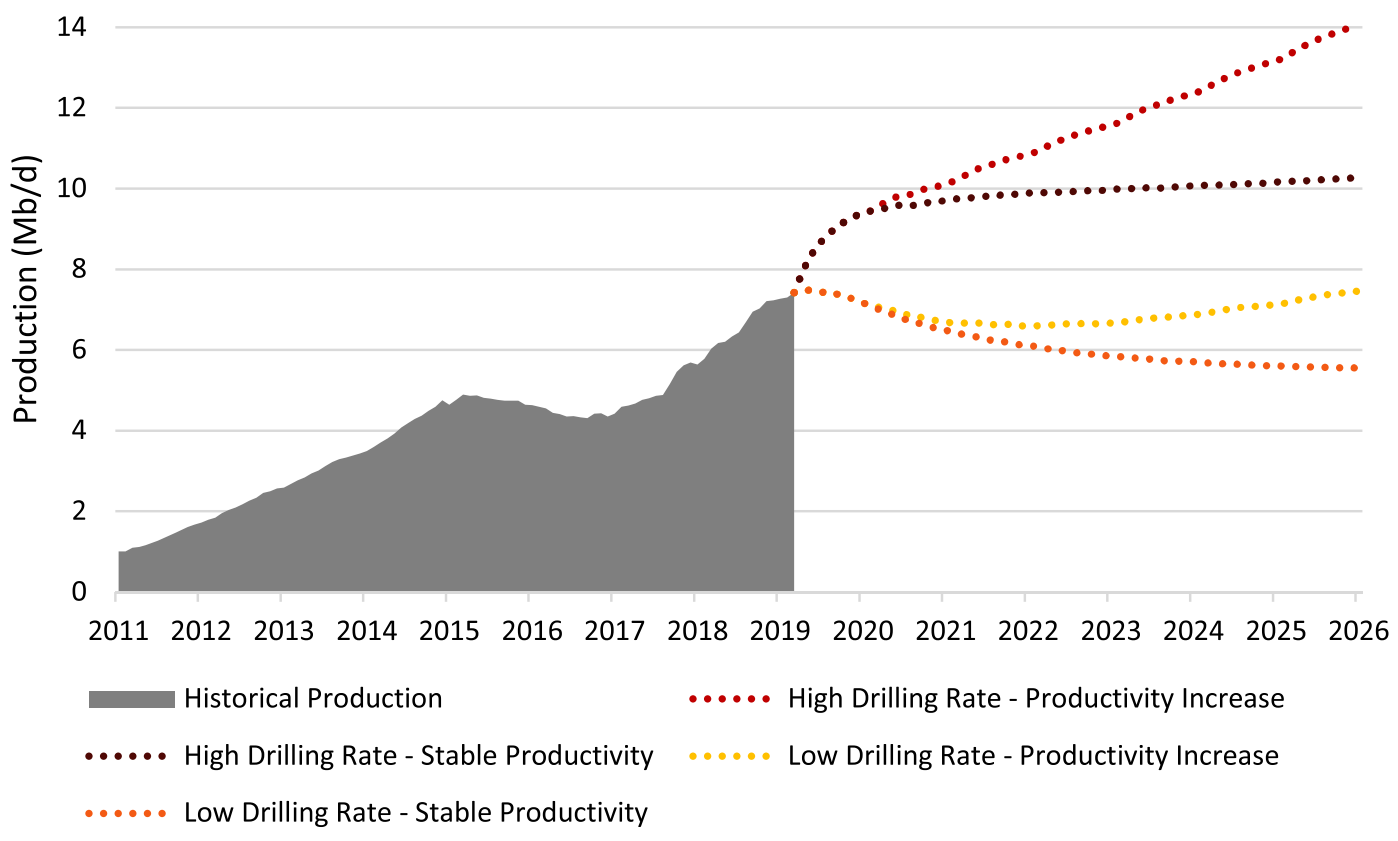

Source: authors, EIA 2019 for historical data

Fig. 9. U.S. Unconventionals historical production data and modelisation results of the different assessed scenarios.

have to turn to less rich areas, which will necessarily have an impact on breakeven prices and productivity in the long term,

- it has been demonstrated that because of the proximity of horizontal wells in unconventionals reservoirs, newly drilled wells could "cannibalize" old wells already in production and lower their productivity (Matthews et al., 2019),

- no economic cut-off is considered in the lifetime of the wells, whereas, most of them are stopped after a certain production time,

- the unconventional activity remains very capital intensive and after many years of high spending, investors are beginning to focus on fiscal discipline, which may limit investment in the future,

- the financial environment, i.e., the low interest rate conditions, could change unfavourably in future years,

- to keep costs low, it is necessary to optimize all equipment as much as possible, which implies the continuous drilling of new wells. This means that companies must constantly have new locations to drill. The competition to acquire new drilling areas in the U.S. is tough. This will have implications on the ability of producers to keep breakeven low over the long term.

It should also be noted that since the beginning of its boom, the U.S. unconventional activity has not been profitable for a single year (Fig. 10). Although some players, notably the majors, can generate profits thanks to a focus on highly productive and profitable acreages, in May 2019, 90\% of independent U.S. producers still did not generate positive cash flow (Rystad Energy, 2019). It can be directly linked to the 185 U.S. oil field services bankruptcies that have been registered since 2015. With a cumulated amount of debt of USD 65 billion, of which USD 25 billion were unsecured that may not be reimbursed, it increases the uncertainties regarding the future of investments in the U.S. unconventional industry (Haynes and Boone's Energy, 2019).

Regarding the last World Energy Outlook (WEO), the IEA also carried out production projections for the U.S. unconventional oil. Their model, which is intended to be more predictive, is consistent with our results and forecasts that production should reach a peak around $9 \mathrm{mb} / \mathrm{d}$ around 2023. When we take a closer look, some of their assumptions are also questionable. In particular, they consider a drilling rate of about 20000 wells per year. Sensitivity analysis shows that the number of wells drilled per year have the greatest impact in our model. Using IEA drilling rate of 20000 wells, our model reaches up to $17.8 \mathrm{mb} / \mathrm{d}$ in 2025 in the productivity increase scenario and $12.9 \mathrm{mb} / \mathrm{d}$ without productivity increase. Nonetheless 20000 wells can be considered as a very optimistic assumption given current and past trends. Considering the current number of active rigs in the U.S. (Fig. 3), it seems very unlikely in the current context of market prices that it will pick-up fast enough to go further the 2011-2014 rates before 2025. On the other hand, and from IEA's point of view, productivity is likely to decrease over time, considering the elements presented above (IEA, 2018). On their side, the EIA is more optimistic with a peak in production that should reach around $12 \mathrm{mb} / \mathrm{d}$ by 2025 in their base case (EIA, 2019). The orders of magnitude are then consistent with our scenario HDR - PI.

In conclusion, through our analysis or the scenarios provided by modelling energy agencies, no current model allows the U.S. unconventionals to reach 15 mbopd of production by 2025. In this context, would it be possible to 


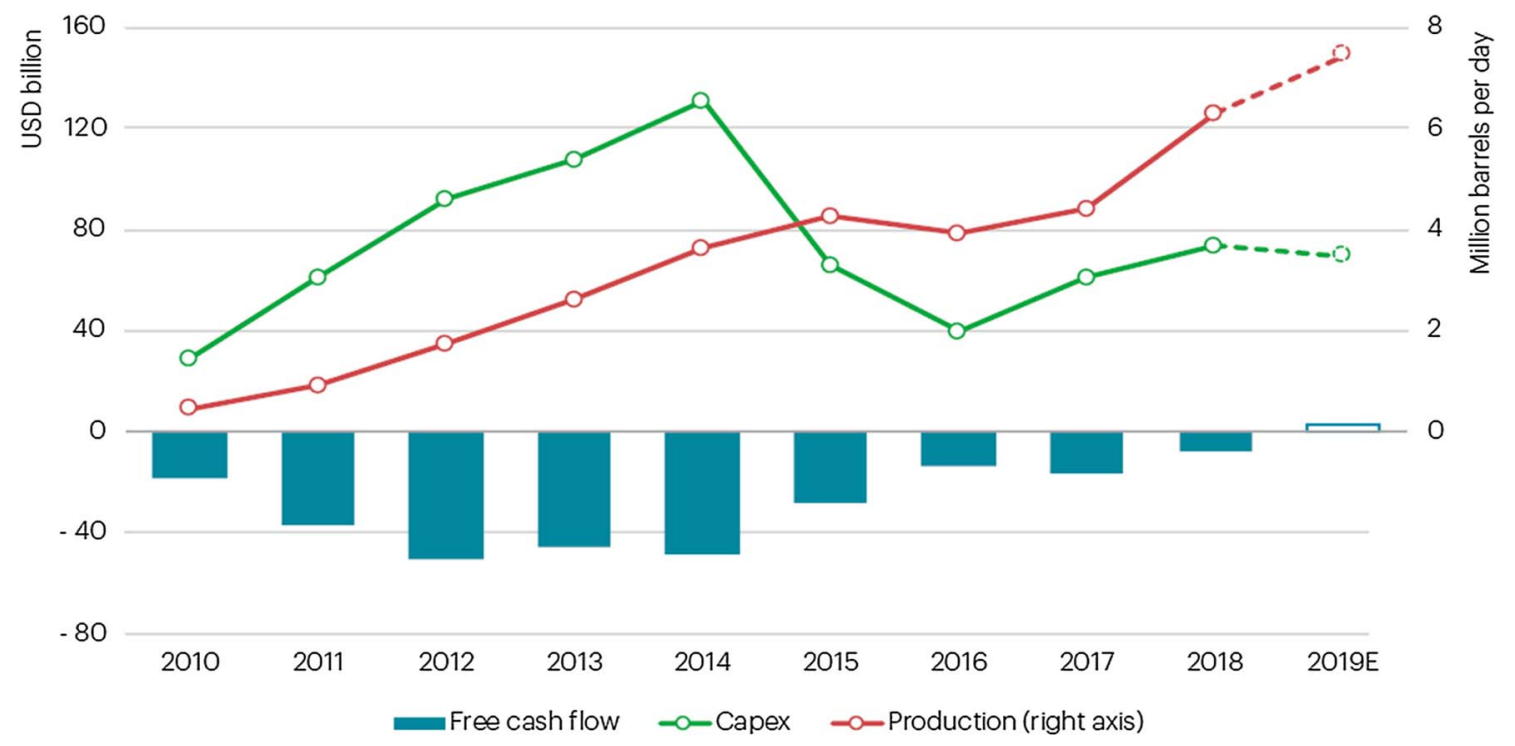

Source: IEA, World Energy Investment 2019

Fig. 10. U.S. Tight oil production, investment and free cash flow.

imagine that the exploitation of other non-conventional resources could emerge in other countries in the same way as in the U.S.? Interests for countries are numerous: energy security, lower gas and electricity prices as well as many jobs that would give a boost to any economy in the world.

Nevertheless the U.S. combined a number of factors in favour of the rapid emergence of the unconventional industry which is unlikely to be observed together elsewhere, included: a close and rapid access to the domestic market (the U.S are the first largest oil consumer in the world), an already well-developed industry with numerous infrastructures (the U.S. is historically in the top three of world producers), companies and universities with extensive knowledge, skills and experience, half of the world drilling rigs, a mature and important investment network, abundant financing resources (large investors panel, highly structured market) as well as specific mining rights giving the subsurface ownership to the landlords (Bauquis, 2014). In areas with high non-conventional production potential (Argentina, China, Russia, etc.) it is unlikely that we will see unconventional production emerge to the extent that has been observed in the U.S., for one or more of the above reasons, depending on local specificities. As an example, China, which should have the means and the resources to penetrate this industry quickly, recently had to reduce their ambitions due to the difficulty of achieving their profitability objectives (Trent, 2019).

In addition, as it was the case at the beginning of the U.S. unconventionals boom, a rapid increase in unconventional production will mechanically create an increase in demand for all the products needed for their extraction such as special sands, viscosifying agents for injection fluids, drilling pipes, rig rental or wages. This increase in demand will lead to higher prices and even supply problems that could reduce the already fragile profitability of some projects (Bauquis, 2014). Therefore, a case-by-case assessment of each country must be considered to assess their real production potential in the medium term, as the factors affecting production costs and project profitability are numerous and different (e.g., rig costs, depth of the reservoir, wages, environmental regulations, state taxes and royalties, resource ownership, etc.).

\section{Conclusion}

In the context of a declining conventional sector (declining production, declining discoveries, insufficient investment, persistent geopolitical risks and environmental pressure) the U.S. unconventionals have emerged as the new opportunity for the Oil and Gas industry to meet the assumed increasing demand. Nevertheless, faced with a demand for oil that would continue to grow in the coming years, the probability of an oil crunch by 2025 is far from null. According to our study, it is unlikely that the U.S. will be able to double their unconventionals production in future years, and, it seems unlikely that another country will be able to put such unconventionals oil volume into production within a few years.

Given the close link that currently exists between energy consumption and global economic growth ${ }^{6}$, it is then difficult to mention the possibility of an oil crunch without mentioning its main possible consequences. The literature already provides analyses of the consequences, mainly economic, of a lack of oil supply on our society, including

\footnotetext{
${ }^{6}$ Indeed, the high rate of economic growth is generally due to industrialization, urbanization, transportation infrastructure, etc., which are mainly dependent on energy consumption such as oil and coal. They are used to produce electricity, heat and fuels for transport (see Waheed et al., 2019 for a complete review of literature).
} 
higher oil prices. While the impacts may vary considerably from one sector and region to another, the transport sector (air, maritime, passenger transport) will be one of the first strongly affected because it is mainly based on the use of liquid fuels. Operations and supply chains disrupted by price increases could quickly result in significant financial losses or bankruptcy. Resulting global high price inflation, combined with uncertain markets, could trigger a world economic recession or a financial crisis, leading to a reduction in global wealth and social issues. Such perspectives and possible consequences cannot be taken lightly and force us today to anticipate and mitigate the risk of a global energy supply contraction. New policies must be set up to minimize the risk of a supply crunch and reduce as much as possible the negative impacts on our societies of such an event.

In addition, the prospect of a slowdown in oil supply strongly reaffirms, in line with global climate objectives, the need for a transition towards an increasingly moderate and efficient use of our energy and the deployment of more renewable capacities. Countries will gain in energy independency and partially reduce the impact of an oil crunch on their economies.

Acknowledgments. This article received the financial support of the French National Research Agency (ANR) through the GENERATE project. The authors would like to thank the anonymous reviewers whose comments and suggestion helped us to improve this article. The authors are also very grateful to Nathalie Keller, François Kalaydjian and Jerome Sabathier for insightful comments and suggestions. Any remaining errors are of course ours. The views expressed herein are strictly those of the authors and are not to be construed as representing those of IFP Energies nouvelles or Equinor.

\section{References}

Bauquis P.R. (2014) Parlons gaz de schiste en 30 questions, La documentation Francaise, France.

BHGE (2019) Baker Hughes Rig Count. https://rigcount.bhge. $\mathrm{com} /$.

Bonnet C., Hache E., Seck G.S., Simoën M., Carcanague S. (2019) Who's winning the low-carbon innovation race? An assessment of countries' leadership in renewable energy technologies, Int. Econ. In press, corrected proof. Available online 22 July 2019.

BP (2018) Statistical review of world energy.

Energy Information Administration (EIA) (2019), https:// www.eia.gov.
Equinor (2018) Energy Perspectives, Long term macro and market outlook, Stavanger, $59 \mathrm{p}$.

Fosse F., Hache E., Portenart P. (2015) Le retour des fusions et acquisitions dans le secteur des hydrocarbures, Rev. l'Energ. 628, 464-478.

Fustier K., Gray G., Gundersen C., Hilboldt T. (2016) Global oil supply. Will mature field declines drive the next supply crunch, HSBC, London.

Grandjean R., Hache E., Seck G.S., Simoën M. (2019) Comprendre les enjeux de la modélisation du lien complexe entre énergie, climat et économie, Rapport The Shift Project et IFPEN, 42 p. https://theshiftproject.org/article/comprendremodelisation-energie-climat-economie-scenarios/.

Hache E. (2016) Un nouvel âge de ruptures sur les marchés de l'énergie? Rev. Int. Stratég. 104, 39-48.

Hache E., Seck G.S., Simoen M., Bonnet C., Carcanague S. (2019a) Critical raw materials and transportation sector electrification: A detailed bottom-up analysis in world transport, Appl. Energy 40, 6-25.

Hache E., Carcanague S., Bonnet C., Seck G., Simoën M. (2019b) Vers une géopolitique de l'énergie plus complexe ? Rev. Int. Stratég. 113, 73-81.

Haynes and Boone's Energy (2019) Energy bankruptcy reports and surveys. https://www.haynesboone.com/Publications/ energy-bankruptcy-monitors-and-surveys.

IFPEN (2019a) Investissements en exploration-production, activités et marchés du forage à terre et en mer, de la géophysique et de la construction offshore en 2018.

IFPEN (2019b) 2019 oil issues: Economic growth, embargo on Iran, OPEP management, "shale oil", IMO standards and more. https://www.ifpenergiesnouvelles.com.

International Energy Agency (IEA) (2018) World energy outlook.

International Energy Agency (IEA) (2019a) World energy investment.

International Energy Agency (IEA) (2019b) Oil 2019, Analysis and forecasts to 2024.

Matthews C.M., Elliott R., Olson B. (2019) Shale companies adding ever more wells, threaten future of U.S. oil boom, Wall Street J., March 3.

Rystad Energy (2018) https://www.rystadenergy.com/newsevents/ news/press-releases/fs-2018-discoveries/, December 21, 2018.

Rystad Energy (2019) Data ucube.

Trent J. (2019) China's shale dream rests atop chaotic geology, J. Pet. Technol. 71, 6, 36-40.

Universum (2019) World's most attractive employers 2018.

Waheed R., Sarwar S., Wei C. (2019) The survey of economic growth, energy consumption and carbon emission, Energy Rep. 5, 1103-1115.

Westwood Global Energy Group (2019) The state of exploration 2019. https://www.westwoodenergy.com/news/westwoodinsight/the-state-of-exploration-2019/. 